\title{
Tirone David valve-sparing aortic root replacement and cusp repair for bicuspid aortic valve disease
}

\author{
Fabian A. Kari, MD, ${ }^{a}$ David H. Liang, MD, PhD, ${ }^{b}$ John-Peder Escobar Kvitting, MD, PhD, ${ }^{a}$ \\ Elizabeth H. Stephens, MD, PhD, ${ }^{a}$ R. Scott Mitchell, MD, ${ }^{a}$ Michael P. Fischbein, MD, PhD, and \\ D. Craig Miller, MD $^{\mathrm{a}}$
}

Objectives: The durability of valve-sparing aortic root replacement with or without cusp repair in patients with bicuspid aortic valve (BAV) disease is questioned. We analyzed the results of 75 patients with a BAV undergoing Tirone David reimplantation valve-sparing aortic root replacement.

Methods: Average age was $45 \pm 10$ years; $80 \%$ were male; $31 \%$ had $2+$ or greater aortic regurgitation (AR); annular diameter averaged $28 \pm 3 \mathrm{~mm} ; 32 \%$ had a Sievers' type $0 \mathrm{BAV}$, and $66 \%$ underwent concomitant cusp repair (usually cusp free margin shortening) to correct prolapse. Early ( $6 \pm 3$ days) and late $(2.9 \pm 1.7,1-10$ years) postoperative echocardiographic results were compared (cumulative echocardiographic follow-up, 190 patient-years; median late interval, 2 years [interquartile range, $0.68,4.2])$. Seven patients remained at risk beyond 6 years. Clinical outcome and valve function were analyzed using log-rank calculations.

Results: Actuarial survival was $99 \% \pm 2 \%$; freedom from reoperation was $90 \% \pm 5 \%$, infection $98 \% \pm 2 \%$, and stroke $100 \%$ at 6 years. After initial improvement in degree of $\operatorname{AR}(P<.001)$, minor subclinical progression of AR was observed $(P>.5)$; however, freedom from AR of more than $2+$ was $100 \%$. Cusp free margin shortening was not associated with valve deterioration, but commissural suspensory polytetrafluoroethylene neochord creation $(\mathrm{n}=4)$ portended a higher probability of recurrent $\operatorname{AR}(P=.025)$.

Conclusions: After David procedure and cusp repair in patients with a BAV, midterm clinical and valve function outcomes were favorable out to 6 years. More follow-up is required to determine long-term valve durability and the hazard of other clinically important late adverse events, including eventual reoperation, to beyond 10 years.

(J Thorac Cardiovasc Surg 2013;145:S35-40)

Supplemental material is available online.

Valve-sparing aortic root replacement (V-SARR) using the David technique combined with cusp repair (CR) has been proposed as a better treatment alternative than valve repair alone or with aortic remodeling or reduction aortoplasty in patients with a bicuspid aortic valve (BAV). ${ }^{1-10}$ Aortic regurgitation (AR) in patients with BAV is commonly due to a dilated, elliptically shaped aortic annulus (El Khoury type I AR) ${ }^{3}$ or cusp diseases, for example, prolapse (El Khoury type II AR), ${ }^{3}$ retraction, fenestrations, or

From the Department of Cardiovascular and Thoracic Surgery ${ }^{a}$ and the Department of Medicine, ${ }^{\mathrm{b}}$ Cardiovascular Medicine Division, Stanford University Medical School, Stanford, Calif.

F.A.K. is currently at the Department of Cardiovascular Surgery, Heart Center Freiburg University, Germany.

J.-P.E.K. is currently at Linköping University Hospital, Department of Cardiothoracic Surgery, Linköping, Sweden.

This work was supported by the U.S.-Norway Fulbright Foundation, the Swedish Heart-Lung Foundation and the Swedish Society for Medical Research (Dr Kvitting).

Disclosures: Dr Mitchell reports consulting fees from W.L. Gore. Dr Fischbein reports consulting fees from Edwards and grant support from the National Marfan Society. Dr Miller reports the following: Consultant to GenTAC/NHLBI under contract to RTI; Consultant to Abbot Vascular Mitraclup; Consultant to Medtronic Cardio Vascular Division Inc; Consultant to PARTNER US immobility, and commonly presents with root dilatation. ${ }^{4}$ Aortic valve repair alone in patients with a malfunctioning $\mathrm{BAV}$ is associated with suboptimal 10-year freedom from reoperation ${ }^{11}$ in part because the aortic annular and root geometric derangements remain uncorrected. Surgical repair should frequently include concomitant replacement or reconstruction of the dilated aortic root and correction of annular dilatation in addition to CR to enhance the durability of the valve repair. ${ }^{4}$

Cusp prolapse can be corrected through a variety of strategies, including free margin shortening, plication, triangular raphé resection, folding in the commissure (Trussler stitch), patching, and commissural closure. Some have

Trial-Percutaneous AVR; Consultant to Medtronic Heart Valve Division; PI for NIH Research Grant; Research Grant from the PARTNER Trial: Placement of Aortic Transcatheter Valve Trial, Edwards LifeSciences. Drs Kari, Liang, Escobar Kvitting, and Stephens have nothing to disclose with regard to commercial support.

Read at the American Association for Thoracic Surgery Aortic Symposium, New York, New York, April 26-27, 2012.

Received for publication Aug 17, 2012; revisions received Aug 17, 2012; accepted for publication Nov 20, 2012; available ahead of print Dec 20, 2012.

Address for reprints: D. Craig Miller, MD, Department of Cardiovascular and Thoracic Surgery, Falk CVRB, Stanford University School of Medicine, Stanford, CA 94305-5247 (E-mail: dcm@stanford.edu). $0022-5223 / \$ 36.00$

Copyright (C) 2013 by The American Association for Thoracic Surgery http://dx.doi.org/10.1016/j.jtcvs.2012.11.043 


Abbreviations and Acronyms
$\begin{aligned} \mathrm{AR} & =\text { aortic regurgitation } \\ \mathrm{BAV} & =\text { bicuspid aortic valve } \\ \mathrm{CPB} & =\text { cardiopulmonary bypass } \\ \mathrm{CR} & =\text { cusp repair } \\ \mathrm{PTFE} & =\text { polytetrafluoroethylene } \\ \mathrm{IQR} & =\text { interquartile range } \\ \mathrm{TEE} & =\text { transesophageal echocardiography } \\ \mathrm{TTE} & =\text { transthoracic echocardiogram } \\ \mathrm{V}-\mathrm{SARR} & =\text { valve-sparing aortic root } \\ & \text { replacement } \\ \mathrm{V}_{\mathrm{S}-\mathrm{MOD}} & =\mathrm{V}-\text { Stanford modification } \\ \mathrm{V}_{\max } & =\text { maximal velocity }\end{aligned}$

reported that valve repair alone is associated with acceptable short-term and midterm results, including low rates of thromboembolism, infection, and early mortality, with acceptable rates of reoperation and freedom from recurrent AR. ${ }^{11-13}$ More contemporary approaches recognize that the annulus and aortic root should also be approached at the time of initial valve repair, including aortic root remodeling (Yacoub), ${ }^{8,12}$ subcommissural annuloplasty (Cabrol stitch), ${ }^{6}$ or V-SARR using the David reimplantation technique. ${ }^{6,9,10}$ Reports of outcome after Tirone David V-SARR in combination with BAV repair, however, are scant. ${ }^{6,10}$ Further, in the presence of a normal aortic root, the wisdom of embarking on an aggressive V-SARR approach to correct an isolated valve problem is uncertain. ${ }^{2-4,10-12,14,15}$

We report midterm results in 75 patients with a BAV who underwent Tirone David V-SARR I $(2 \%)$ or Tirone David V-Stanford modification $\left(\mathrm{V}_{\mathrm{S}-\mathrm{MOD}}, 98 \%\right)$; $\mathrm{CR}$ was carried out in $66 \%$.

\section{METHODS}

\section{Patients and Procedures}

Seventy-five patients with a BAV (normally functioning or regurgitant) who underwent Tirone David V-SARR or $\mathrm{V}_{\mathrm{S}-\mathrm{MOD}}$, with or without concomitant CR, between 1997 and 2011 were included. See Table 1 for patient characteristics. The distribution of Sievers' BAV configuration types, ${ }^{15}$ preoperative valve function, and BAV-associated aortopathy (Fazel-Stanford clusters ${ }^{16}$ ) are summarized in Tables 2 and 3. Thirty (39\%) patients had no AR, $22(29 \%)$ had $1+$ AR, but $23(31 \%)$ had $2+$ or more AR ( 8 had 4+ AR) (Table 2). See Appendix E1 for more details.

\section{End Points}

The primary end points were freedom from death and freedom from reoperation owing to any cause. Intraoperative echocardiographic end points were postrepair cusp coaptation height, grade of residual AR, mean and peak aortic gradients, and maximal velocity $\left(\mathrm{V}_{\max }\right)$. Follow-up echocardiographic end points were freedom from AR greater than $2+$, transvalvular gradients, and $\mathrm{V}_{\max }$.

\section{RESULTS \\ Annular Dimension Change}

The median proximal graft size was $34 \mathrm{~mm}$ (range, 30-38 $\mathrm{mm}$; interquartile range [IQR], 33-34 mm), which was necked down over a valve sizer to a median annular external diameter of $27 \mathrm{~mm}$ (range, 21-31 mm; IQR, 27-27 mm). This reduced the annular dimension from $27.9 \pm 2.9 \mathrm{~mm}$ preoperatively to $23.1 \pm 2.2 \mathrm{~mm}$ postoperatively $(P<.001)$. In 7 patients without preoperative annular dilation, annular diameter was unchanged. For the other 68 $(91 \%)$ patients the annulus was more than $5 \mathrm{~mm}$ smaller in 39, more than $6 \mathrm{~mm}$ smaller in 26 , and more than 7 $\mathrm{mm}$ smaller in 20. Annular size reduction was not associated with increased need for CR (number of free margin shortening sutures, $P>.05$ ). Furthermore, annular dimension reduction over $5 \mathrm{~mm}$ did not have any significant impact on recurrent AR by log-rank analysis $(P>.05)$. Patients who had annular dimension reduction exceeding $6 \mathrm{~mm}$, however, were more likely to have AR greater than $2+$ late postoperatively $(P=.02)$.

\section{Survival}

The mean follow-up interval was 3 years (range, 7 days to 9.2 years; 25th and 75th percentiles, 224 days and 1521 days, respectively). Cumulative follow-up was 190 patient-years. There was 1 early postoperative death owing to right ventricular failure precipitated by injury to a small, nondominant right coronary artery in a 20 -year-old woman after V-SARR and total arch replacement in 1997. No late deaths have occurred to date, resulting in an actuarial survival estimate of $98 \% \pm 2 \%$ at 3 months.

\section{Reoperation}

Freedom from any reoperation was $90 \% \pm 5 \%$ at 2.8 years (3 events, only 2 of which were valve related, Figure 1). See Appendix E1 for further details. Log-rank tests showed no difference in freedom from reoperation between patients who had cusp free margin shortening compared with those who did not $(P=.8)$. Similarly, there was no difference in reoperation pivoting on BAV configuration type (Sievers' type 1 [S1, one raphé] vs Sievers' type 0 [S0, no raphé, "naturally perfect"], $P=.268){ }^{15}$

\section{Endocarditis and Thromboembolism}

There were no cases of endocarditis aside from the patient described (Appendix E1), who required reoperation. Freedom from endocarditis was $98 \% \pm 2 \%$ at 8 months. There were no strokes or major systemic thromboembolic complications, but 1 patient had a transient ischemic attack late postoperatively without any permanent deficit.

\section{Intraoperative Valve Hemodynamic Function}

The aortic mean gradient was $7.6 \pm 3.3 \mathrm{~mm} \mathrm{Hg}$, peak gradient was $13.6 \pm 6 \mathrm{~mm} \mathrm{Hg}$, and $\mathrm{V}_{\max }$ was $176.9 \pm 41$ 
TABLE 1. Baseline characteristics and procedure details for the 75 patients with bicuspid aortic valves undergoing David valve-sparing aortic root replacement

\begin{tabular}{lc}
\hline Age, $\mathrm{y}$, mean $\pm \mathrm{SD}$ (range) & $45 \pm 10(20-64)$ \\
Gender & \\
Male, $\mathrm{n}(\%)$ & $60(80)$ \\
Female, $\mathrm{n}(\%)$ & $15(20)$ \\
Height, $\mathrm{cm}$, mean $\pm \mathrm{SD}$ (range) & $172 \pm 30(155-198)$ \\
Weight, $\mathrm{kg}$, mean $\pm \mathrm{SD}$ (range) & $86 \pm 16(56-135)$ \\
Marfan syndrome, $\mathrm{n}(\%)$ & $7(9)$ \\
Loeys-Dietz syndrome, $\mathrm{n}(\%)$ & 0 \\
Acute aortic dissection, $\mathrm{n}(\%)$ & 0 \\
Left ventricular EF, $\%$, mean $\pm \mathrm{SD}$ (range) & $60 \pm 4(50-70)$ \\
Aortic regurgitation (any), $\mathrm{n}(\%)$ & $46(61)$ \\
Aortic root replacement & $75(100)$ \\
Tirone David I, $\mathrm{n}(\%)$ & $2(3 \%)$ \\
Tirone David $\mathrm{V}_{\mathrm{S}-\mathrm{MOD}}, \mathrm{n}(\%)$ & $73(97 \%)$ \\
Previous CV surgery, $\mathrm{n}(\%)$ & $4(5)$ \\
Prior coarctation repair & 4 \\
Concomitant cardiac procedure, $\mathrm{n}(\%)$ & $2(3)$ \\
Mitral valve repair & 2 \\
Transverse arch replacement, $\mathrm{n}(\%)$ & $48(64)$ \\
Peninsula technique, partial & 45 \\
Peninsula technique, total & 3 \\
Cusp free margin repair, $\mathrm{n}(\%)$ & $50(67)$ \\
$\geq$ One cusp free margin shortening stitch & 50 \\
Triangular raphé resection & $7(9)$ \\
Commissural suspensory neochord creation (PTFE) & $3(4)$ \\
\hline
\end{tabular}

$S D$, Standard deviation; $E F$, ejection fraction; $V_{S-M O D}, \mathrm{~V}-$ Stanford modification; $C V$, cardiovascular; PTFE, polytetrafluoroethylene (Gore-Tex; W. L. Gore \& Associates, Inc, Flagstaff, Ariz)

$\mathrm{cm} / \mathrm{s}$ preoperatively. Transesophageal echocardiography (TEE) after weaning from cardiopulmonary bypass (CPB) showed that the postrepair coaptation height achieved by V-SARR reduction of annular size and CR was $9 \pm 0.9$ $\mathrm{mm}$. Two patients had $1+$ (mild) AR; the other patients had either no $(74 \%)$ or trace $(15 \%)$ AR. Post-CPB TEE aortic valve mean gradient was $6.8 \pm 4.9 \mathrm{~mm} \mathrm{Hg}$, peak gradient was $14.1 \pm 1.8 \mathrm{~mm} \mathrm{Hg}$, and $\mathrm{V}_{\max }$ averaged $180 \pm 60$ $\mathrm{cm} / \mathrm{s}$ (not significant vs preoperative condition for all).

\section{Early and Late Postoperative Valve Function}

The median time of the early postoperative TTE was 5 days (IQR, 4-6 days; mean, $6 \pm 3$ days; range, 3-19 days); for the latest echocardiographic assessment, the median time was 2.4 years (IQR, 1.6-4.2 years; mean, $3 \pm 1.9$ years; range, 67-9.2 years). AR grade changed from a preoperative median of $1(\mathrm{IQR}, 0-2)$ to a median of $0(\mathrm{IQR}, 0)$ at the time of the early TTE study $(P<.001$, Wilcoxon); mean gradient $(6.8 \pm 4.9 \mathrm{~mm} \mathrm{Hg}$ vs $8.5 \pm 3.5 \mathrm{~mm} \mathrm{Hg})$, peak gradient $(14.1 \pm 8 \mathrm{~mm} \mathrm{Hg}$ vs $15.1 \pm 5.3 \mathrm{~mm} \mathrm{Hg})$, and $\mathrm{V}_{\max }$ $(180 \pm 60 \mathrm{~cm} / \mathrm{s}$ vs $194 \pm 44 \mathrm{~cm} / \mathrm{s})$ were unchanged.

At the time of the latest TTE follow-up examination, the median AR grade was 0 (IQR, 0-1), unchanged compared with the early postoperative TTE. The late postoperative mean gradient was $12.1 \pm 5.6 \mathrm{~mm} \mathrm{Hg}$, peak gradient $22 \pm 11 \mathrm{~mm} \mathrm{Hg}$, and $\mathrm{V}_{\max } 229 \pm 56 \mathrm{~cm} / \mathrm{s}$, indicating no increase in degree of aortic stenosis over time.

In 19 patients there was progression of AR over time (Figure 2). Sixteen patients went from none to $1+\mathrm{AR}, 2$ from none to $2+$, and 1 from $1+$ to $2+$. By log-rank tests, CR $(P=.358)$, number of free margin sutures placed $(P=.373)$, cusp fibrosis or sclerosis $(P=.348)$, and $\mathrm{Si}-$ evers' BAV type $(P=.66)$ did not have any significant impact on freedom from AR progression over time. AR as a function of time is illustrated in Figure 2.

\section{DISCUSSION}

Decision-making in this experience was uniform with respect to whether or not CR was performed. All underwent V-SARR $\left(98 \%\right.$, Tirone David $\left.\mathrm{V}_{\mathrm{S}-\mathrm{MOD}}\right) .{ }^{14}$ In contrast, root reconstruction techniques varied widely in other series, and David V-SARR was used sparingly. Aicher and associates ${ }^{1}$ reported on 316 patients with a BAV who underwent repair: one hundred had subannular plication, 122 root remodeling (David II), and $2(0.6 \%)$ patients had aortic root reimplantation. In 2005, Alsoufi and coworkers ${ }^{17}$ published a series of 71 patients from Toronto who underwent repair of a BAV; 13 had root remodeling and had 16 David

TABLE 2. Preoperative geometry, BAV configuration types according to Sievers' classification, and aortic valve hemodynamic function for the 75 BAV patients. $P$ values derived from ANOVA on ranks

\begin{tabular}{|c|c|c|c|c|c|c|c|c|}
\hline & $\begin{array}{c}\text { All } \\
(n=75)\end{array}$ & $\begin{array}{c}\text { S0/lat } \\
(n=17)\end{array}$ & $\begin{array}{c}\text { S0/ap } \\
(\mathbf{n}=7)\end{array}$ & $\begin{array}{c}\text { S1/L-R } \\
(n=44)\end{array}$ & $\begin{array}{l}\text { S1/R-N } \\
(n=5)\end{array}$ & $\begin{array}{l}\text { S1/N-L } \\
(n=2)\end{array}$ & $\begin{array}{c}\text { S2 } \\
(\mathbf{n}=\mathbf{0})\end{array}$ & $\boldsymbol{P}$ \\
\hline $\mathrm{AR}, \mathrm{n}(\%)$ & $45(60)$ & $7(42)$ & $4(57)$ & $33(75)$ & $1(20)$ & 0 & - & .008 \\
\hline El Khoury type I (annular dilation), n (\%) & $9(12)$ & $3(18)$ & $1(14)$ & $4(1)$ & $1(25)$ & 0 & - & .571 \\
\hline Annular diameter $\mathrm{mm}$, mean $\pm \mathrm{SD}$ (range) & $28 \pm 2.9$ & $27.8 \pm 3.1$ & $29.5 \pm 2.2$ & $27.7 \pm 2.8$ & $27.2 \pm 3.1$ & $29 \pm 5.7$ & - & .56 \\
\hline El Khoury type II (cusp prolapse), n (\%) & $45(60)$ & $10(59)$ & $4(57)$ & $27(61)$ & $2(40)$ & $2(100)$ & - & .821 \\
\hline No/trivial (0) AR, n (\%) & $30(39)$ & $10(59)$ & $3(43)$ & $11(25)$ & $4(80)$ & $2(100)$ & - & .008 \\
\hline Mild $(1+)$ AR, n $(\%)$ & $22(29)$ & $4(24)$ & $2(29)$ & $15(34)$ & $1(20)$ & 0 & - & .777 \\
\hline Moderate $(2+)$ AR, n (\%) & $13(17)$ & $3(18)$ & $2(29)$ & $8(18)$ & 0 & 0 & - & .655 \\
\hline Moderate-severe $(3+)$ AR, n (\%) & $2(3)$ & 0 & 0 & $2(5)$ & 0 & 0 & - & .833 \\
\hline Severe $(4+)$ AR, n (\%) & $8(12)$ & 0 & 0 & $8(18)$ & 0 & 0 & - & .173 \\
\hline Median AR grade (IQR) & $1(0-2)$ & $0(0-0)$ & $1(0-2)$ & $1(1-2)$ & 0 & 0 & - & .006 \\
\hline Aortic stenosis $(\%)$ & 0 & 0 & 0 & 0 & 0 & 0 & - & - \\
\hline
\end{tabular}

$B A V$, Bicuspid aortic valve; $A N O V A$, analysis of variance; $A R$, aortic regurgitation; $S D$, standard deviation; $I Q R$, interquartile range. 
TABLE 3. Distribution of preoperative radiographic aneurysmal disease according to Stanford-Fazel clusters of BAV-associated aortopathy in $75 \mathrm{BAV}$ patients based on CTA or MRA imaging

Cluster I (root only), n (\%) $34(45.3)$

Intermediate cluster I-II (root + Asc Ao), $\mathrm{n}(\%)$ $19(25)$

Cluster II (normal root, Asc Ao, normal arch), n (\%)

$1(1.3)$

Cluster III (normal root, Asc Ao and Ao arch), n (\%)

$16(21.3)$

Cluster IV (root + Asc Ao + arch), n (\%) $24(32)$

$B A V$, Bicuspid aortic valve; $C T A$, computed tomographic angiography; $M R A$, magnetic resonance angiography; Asc Ao, ascending aorta; Ao arch, aortic arch.

V-SARR $(23 \%)$. The Mayo group ${ }^{11}$ repaired a regurgitant BAV in 108 patients (average age, 41 years), but some type of aortic graft or reduction aortoplasty was carried out in only $21 \%$, reflecting the isolated valve approach that does not correct simultaneously annular and root pathologic conditions. This may explain why only $49 \%$ of patients at 10 years were free from reoperation for AVR, but follow-up was long (23 years, average follow-up time, $5.1 \pm 4.1$ years).$^{11}$ El Khoury's unit ${ }^{4}$ in Brussels earlier reported on 122 patients undergoing BAV repair, 34\% of whom underwent David V-SARR. Badiu and colleagues ${ }^{2}$ repaired BAV in 43 patients, but only $16(37 \%)$ had aortic root reimplantation. A comprehensive analysis of $161 \mathrm{pa}-$ tients with a BAV by de Kerchove and colleagues ${ }^{6}$ from El Khoury's unit recently compared the midterm results after either elective David V-SARR or lesser procedures including Yacoub remodeling with Cabrol subcommissural annuloplasty or no annuloplasty. The 2 groups were matched for aortic root dimension and degree of AR. Survival was similar to beyond 5 years, but the rates of late

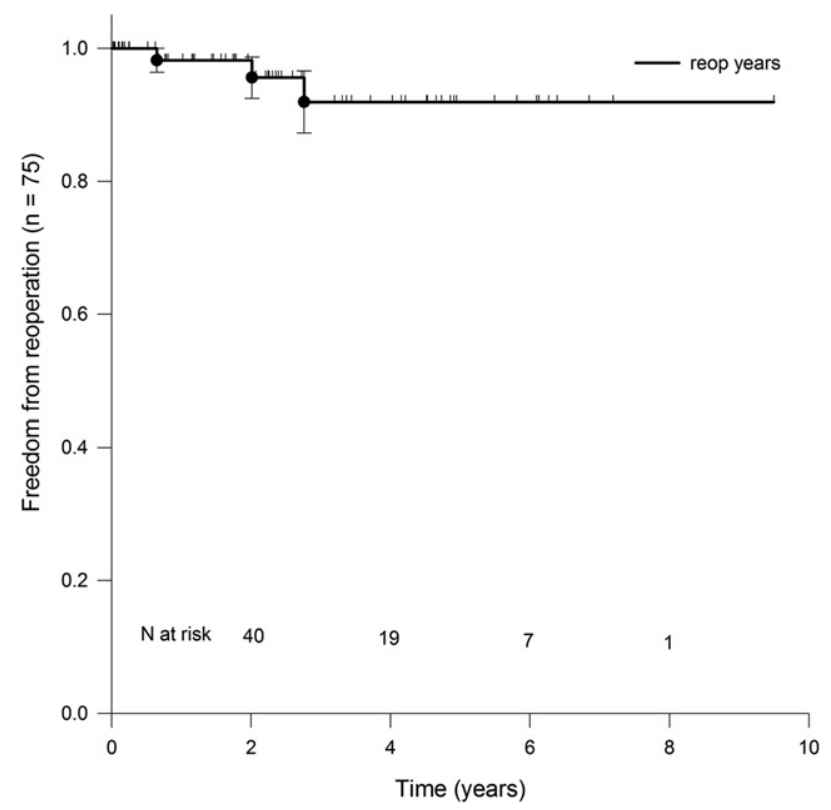

FIGURE 1. Kaplan Meier estimate of freedom from reoperation for 75 patients with bicuspid aortic valve undergoing valve-sparing aortic root replacement. Error bars indicate \pm 1 standard error of the mean.

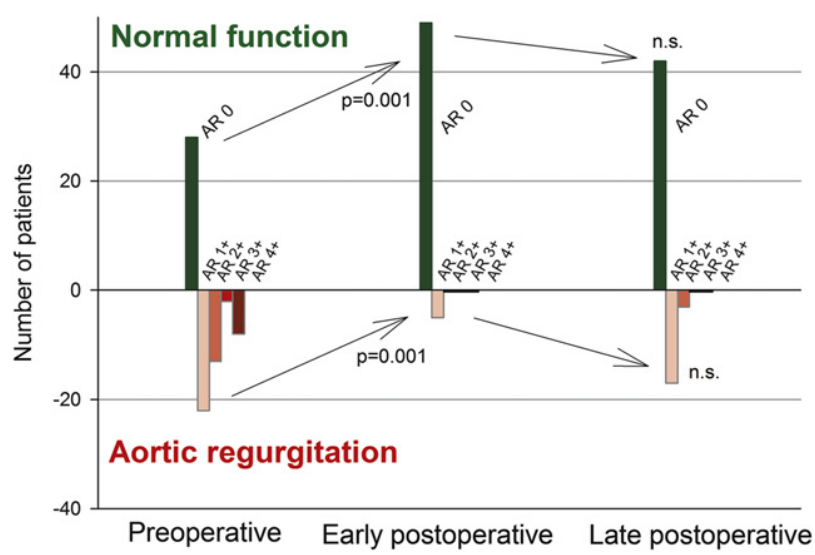

FIGURE 2. Preoperative, early postoperative, and late postoperative degrees of echocardiographic aortic regurgitation. See text for details of the timing of the postoperative echocardiograms. n.s., Not significant.

reoperation and recurrent $\mathrm{AR}$ were significantly lower in the V-SARR group. These observations represent compelling arguments favoring formal V-SARR in terms of valve repair durability, even if the aortic root is normal. ${ }^{6}$ Similar recommendations have been voiced by De Paulis. ${ }^{7}$

In our experience, $66 \%$ of patients required some sort of $\mathrm{CR}$, usually free margin shortening sutures. This parallels the trends reported from Homburg (88\% plication) ${ }^{1}$ Toronto (62\% plication), ${ }^{17}$ and the Mayo Clinic (94\% commissural plication, with either raphé excision or plication [since 2000]). ${ }^{11}$ In only 7 of our patients was plication combined with triangular raphé resection, which differs from its frequent use in other institutions and was the most common technique in the Mayo experience. ${ }^{11}$ Scarring, fibrosis, and calcification of the cusps were similar, for example, $35 \%$ in our series versus $45 \%$ in the Mayo report. ${ }^{11}$ Inasmuch as patient age could be a potential confounder, it is noteworthy that these patient cohorts had mean ages of $41.5 \pm 13.2$ years in Toronto ${ }^{17} 41 \pm 13$ years at Mayo, ${ }^{11} 49 \pm 14$ years in Homburg, ${ }^{1}$ and $45 \pm 10$ years in our current series.

We avoid triangular raphé resection or formal cusp plication whenever possible so as not to impair cusp mobility. If the 2 fused cusps are thin, not excessively prolapsing, and the raphé is not densely fibrotic or calcified, free margin shortening is usually adequate. The echocardiographic results reported herein demonstrated no significant postoperative increase of aortic stenosis.

Cusp patch repair (used in as many as $18 \%$ of patients in a report from Brussels ${ }^{3}$ ) was not performed. It correlates with higher reoperation rates and overall worse outcome, with a hazard ratio of 7.6 for reoperation. ${ }^{3}$ None of the 75 patients with BAV had El Khoury type Id AR owing to perforation, which might necessitate a patch. At Stanford, bicuspid valves with type Id AR with large perforations are replaced. Further, we do not resort to subcommissural plication annuloplasty (Cabrol) in the management of the dilated aortic annulus, as has been routinely done by others in the 
past, ${ }^{3}$ because the David V-SARR corrects the dilated annulus in a definitive and reliable fashion. Subcommissural maneuvers predicted inferior late valve function and more reoperations in the latest report from Schäfers's unit ${ }^{1}$ in Homburg (hazard ratio, 2.07; univariable analysis only).

Boodhwani and associates ${ }^{4}$ (from El Khoury's unit) in 2010 reported 8-year freedom from reoperation after repair of BAV to be as high as $83 \%$. Freedom from other adverse events such as thromboembolism was $96 \%$ at 8 years. ${ }^{4}$ In the most recent Brussels report ${ }^{6}$ for patients undergoing David V-SARR, the freedom from reoperation and recurrent $2+$ AR or greater estimates were $100 \%$ at 5 years, similar to our observations. Our findings add to a growing body of evidence that the most definitive and reliable approach to repair a regurgitant BAV is David V-SARR, even if the aortic root is normal. In experienced centers, the early risk is no higher than that associated with lesser procedures, but the midterm results are superior.

Excessive cusp plication induces the potential danger of creating aortic stenosis acutely by impairing cusp mobility or over the long term by inducing fibrotic cusp remodeling. ${ }^{6}$ Reducing cusp mobility may also lead to recurrent or progressive AR. ${ }^{6}$ In our experience, free margin shortening did not reduce cusp area or abolish mobility; the number of free margin shortening stitches did not correlate with AR progression. On the basis of our results primarily using free margin shortening, we suggest that formal full cusp plication should be performed only rarely. If the fused cusps are prolapsing markedly and upward of $1 \mathrm{~cm}$ of tissue redundancy is present or the cusp free margin at the raphé is fibrotic, then a small triangular raphé resection is reasonable.

Hanke and colleagues ${ }^{18}$ carried out an elegant statistical analysis of factors that portend more AR progression after V-SARR in 84 patients. They identified cusp plication as a predictor of progressive AR. Conversely, the only independent predictor of AR progression that we identified was creation of neosuspensory chords using polytetrafluoroethylene (PTFE) sutures (Gore-Tex; W. L. Gore \& Associates, Inc, Flagstaff, Ariz), which we have abandoned. These primitive BAVs mimic quadricuspid truncal valves and today are replaced at Stanford unless compelling indications are present that militate against AVR.

Fixation and especially downsizing of the annulus using David V-SARR is one of the most important benefits when treating patients with a BAV who have dilated and/or elliptical annuli. We found that reduction by more than $6 \mathrm{~mm}$ might be linked to more postoperative AR (higher rates of $\mathrm{AR}>1+$ ). Inasmuch as overall there were only 3 patients with $\mathrm{AR} 2+$ and freedom from AR greater than $2+$ was $100 \%$, this caveat must be interpreted cautiously. This finding needs to be validated in large cohort studies.

Overall, there was a slight trend toward progression of AR with a median freedom from AR progression of 4.5 years. Most of the patients, however, went from 0 to $1+$ $\mathrm{AR}$ at the 6- to 12-month TEE examination and stabilized thereafter. Whether this translates into more severe AR and more obligatory reoperations in the future remains unknown, but we realistically do not expect these BAVs to function satisfactorily as long as trileaflet aortic valves after V-SARR. Preoperatively, the patients must accept that they are trading the avoidance of anticoagulation for a low, but finite, risk of reoperation within 10 to 30 years. This is why we do not favor sparing the BAV in older patients who are in their 60s inasmuch as progression of aortic stenosis is unpredictable and they have fewer years to benefit from avoiding anticoagulation. Alternatively, replacing a BAV in a patient in his or her late $50 \mathrm{~s}$ or $60 \mathrm{~s}$ with a bioprosthetic valve graft (or "Bio-root") is attractive despite the relative young age because the substitute bioprosthesis will constitute a more favorable landing zone than the native BAV for possible transcatheter valve replacement.

Given the favorable midterm outcomes in our experience and the results of other experienced aortic centers, ${ }^{4,6,7,10}$ reconstructive approaches incorporating David V-SARR are justified for many selected patients who have a regurgitant or normally functioning BAV with or without associated aortic root aneurysmal disease. The introduction of repair-oriented terminology systems to describe the mechanism of AR by Boodhwani and colleagues ${ }^{3}$ from El Khoury's group and a more refined understanding of the mechanisms causing $\mathrm{AR}^{19}$ have improved reparative techniques for bicuspid valves. A key decision is to abandon preservation of a bicuspid valve where the cusps are fibrotic, calcified, attenuated, and/or fenestrated, or otherwise pathologically damaged, as such will lead to suboptimal results; these valves should be replaced. Comparison of various BAV repair techniques and strategies for the aortic root in prospective randomized trials has not and realistically will probably never be carried out. Long-term outcomes beyond 10 years remain unknown. Adverse events will continue to occur as these young patients age, mandating caution and exceedingly careful patient selection at this point until 10- to 20-year surgical results become available.

\section{Limitations}

In this series of V-SARR for BAV disease, few patients remained at risk beyond 5 years. The "critical" $(10 \%$ of initial sample size) number of patients remaining at risk was at 7 years. Our results should thus be considered midterm only.

This was a retrospective study, although most of the clinical and valvular parameters were collected prospectively. Annular diameters were documented prospectively during the operation but validated retrospectively by computed tomographic angiography measurements. 
Overall, the small number of adverse events precluded using a hazard model to identify patient- or diseaserelated variables predicting less salutary outcomes. Our log-rank significant findings for rare end points such as AR grade greater than $1+$ must therefore be interpreted with caution. Specifically, we found that reduction of the annulus by more than $5 \mathrm{~mm}$ might be linked to more AR (higher rates of $\mathrm{AR}>1+$ ). With only 3 patients having an $\mathrm{AR}$ of $2+$ and freedom from AR greater than $2+$ being $100 \%$, this link must be considered preliminary.

Clinically important events (stroke, hemorrhagic events, infection, structural valve deterioration, reoperation) happen rarely and late postoperatively, which highlights the need of future long-term investigations of V-SARR for patients with BAV disease. Randomized, prospective studies would be prohibitively expensive and probably unrealistic. Thus, we must rely on retrospective observations: the statistical power of retrospective studies can be increased in the future by performing large meta-analyses.

This experience included selected young patients with BAV undergoing elective, first-time V-SARR, with probable patient-referral and patient-selection biases. One surgeon (D.C.M.) operated on all patients, making generalization of the results to other surgeons or institutions speculative.

We acknowledge Michael Sheehan, MSN, RNFA, NPc for his efforts in following up patients and capturing the late echocardiographic images.

\section{References}

1. Aicher D, Kunihara T, Abou Issa O, Brittner B, Graber S, Schafers HJ. Valve configuration determines long-term results after repair of the bicuspid aortic valve. Circulation. 2011;123:178-85.

2. Badiu CC, Bleiziffer S, Eichinger WB, Zaimova I, Hutter A, Mazzitelli D, et al. Are bicuspid aortic valves a limitation for aortic valve repair? Eur J Cardiothorac Surg. 2011;40:1097-104.

3. Boodhwani M, de Kerchove L, Glineur D, Poncelet A, Rubay J, Astarci P, et al. Repair-oriented classification of aortic insufficiency: impact on surgical techniques and clinical outcomes. J Thorac Cardiovasc Surg. 2009;137: 286-94.
4. Boodhwani M, de Kerchove L, Glineur D, Rubay J, Vanoverschelde JL, Noirhomme P, et al. Repair of regurgitant bicuspid aortic valves: a systematic approach. J Thorac Cardiovasc Surg. 2010;140:276-84.e1.

5. Boodhwani M, El Khoury G. Principles of aortic valve repair. J Thorac Cardiovasc Surg. 2010;140(6 Suppl):S20-2; discussion S45-51.

6. de Kerchove L, Boodhwani M, Glineur D, Vandyck M, Vanoverschelde JL, Noirhomme P, et al. Valve-sparing root replacement with the reimplantation technique to increase the durability of bicuspid aortic valve repair. $J$ Thorac Cardiovasc Surg. 2011;142:1430-8.

7. De Paulis R. Aortic root surgery: from valve sparing to 'spare and plasty.' Eur J Cardiothorac Surg. 2010;38:513-4.

8. Doss M, Risteski P, Sirat S, Bakhtiary F, Martens S, Moritz A. Aortic root stability in bicuspid aortic valve disease: patch augmentation plus reduction aortoplasty versus modified David type repair. Eur J Cardiothorac Surg. 2010;38:523-7.

9. Svensson LG, Batizy LH, Blackstone EH, Gillinov AM, Moon MC, D'Agostino RS, et al. Results of matching valve and root repair to aortic valve and root pathology. J Thorac Cardiovasc Surg. 2011;142:1491-8.e7.

10. Svensson LG, Kim KH, Blackstone EH, Rajeswaran J, Gillinov AM, Mihaljevic T, et al. Bicuspid aortic valve surgery with proactive ascending aorta repair. J Thorac Cardiovasc Surg. 2011;142:622-9, 9 e1-3.

11. Ashikhmina E, Sundt TM 3rd, Dearani JA, Connolly HM, Li Z, Schaff HV. Repair of the bicuspid aortic valve: a viable alternative to replacement with a bioprosthesis. J Thorac Cardiovasc Surg. 2010;139:1395-401.

12. Aicher D, Fries R, Rodionycheva S, Schmidt K, Langer F, Schafers HJ. Aortic valve repair leads to a low incidence of valve-related complications. Eur J Cardiothorac Surg. 2010;37:127-32.

13. Pettersson GB, Crucean AC, Savage R, Halley CM, Grimm RA, Sevensson LG, et al. Toward predictable repair of regurgitant aortic valves-a systematic morphology-directed approach to bicommissural repair. J Am Coll Cardiol. 2008;52:40-9.

14. Demers P, Miller DC. Simple modification of "T. David-V" valve-sparing aortic root replacement to create graft pseudosinuses. Ann Thorac Surg. 2004;78: 1479-81.

15. Sievers HH, Schmidtke C. A classification system for the bicuspid aortic valve from 304 surgical specimens. J Thorac Cardiovasc Surg. 2007;133:1226-33.

16. Fazel SS, Mallidi HR, Lee RS, Sheehan MP, Liang D, Fleischman D, et al. The aortopathy of bicuspid aortic valve disease has distinctive patterns and usually involves the transverse aortic arch. J Thorac Cardiovasc Surg. 2008;135: 901-7, 7 e1-2.

17. Alsoufi B, Borger MA, Armstrong S, Maganti M, David TE. Results of valve preservation and repair for bicuspid aortic valve insufficiency. $J$ Heart Valve Dis. 2005;14:752-8; discussion 8-9.

18. Hanke T, Charitos EI, Stierle U, Robinson D, Gorski A, Sievers HH, et al. Factors associated with the development of aortic valve regurgitation over time after two different techniques of valve-sparing aortic root surgery. $J$ Thorac Cardiovasc Surg. 2009; 137:314-9.

19. Augoustides JG, Szeto WY, Bavaria JE. Advances in aortic valve repair: focus on functional approach, clinical outcomes, and central role of echocardiography. J Cardiothorac Vasc Anesth. 2010;24:1016-20. 


\section{APPENDIX E1 \\ Methods}

Operative techniques. If transverse arch replacement was carried out, CPB arterial cannulation usually used a 6- to 8-mm Dacron graft sutured to the innominate artery for CPB and selective antegrade cerebral perfusion. The original Feindel-David formula (graft diameter $\approx$ [average cusp height $\cdot 2 \cdot 0.67]+2$ aortic wall thickness) determined the nominal size of the proximal graft, but recently we have used larger graft sizes. The Stanford modification of the Tirone David-V V-SARR technique is described elsewhere. ${ }^{14}$

Four patients without any cusp prolapse initially had some degree of prolapse after a root replacement procedure requiring free margin repair. CR procedures included placement of 5-0 or 6-0 PTFE or braided polyester sutures at the nodulus of Arantius and/or peripherally to shorten the cusp free margin, triangular raphé resection, suspensory neocord creation with 4-0 or 5-0 PTFE suture, or combinations of these techniques, as illustrated in Figure E1. Formal cusp plication from the free margin to the cusp hinge was not used. Figure E2 shows the different CR techniques subdivided according to type of BAV and cusp location.

Data assessment and statistical analysis. Informed consent was obtained; the Stanford University Institutional Review Board approved this study. Details of valve configuration, specifics of location and severity of prolapsing cusps, and details of specific CRs were retrospectively extracted from operative reports. The pathologic BAV cusp configuration according to Sievers' types was confirmed and cusp lesions such as thickening, fibrosis, or calcification were noted intraoperatively. Localization and severity of cusp prolapse was documented. After valve reimplantation into the proximal graft, cusp coaptation height and prolapse were again assessed to determine whether cusp free margin shortening was necessary.

Intraoperative TEE before and after root reimplantation was used to measure gradients, $\mathrm{V}_{\max }$, cusp coaptation heights, and residual AR. All patients had a predischarge transthoracic echocardiogram (TTE) early postoperatively; annual TTE was recommended thereafter, but not universally carried out. Late postoperative echocardiographic images were obtained whenever possible from outside institutions and analyzed by an experienced echocardiographer (D.H.L.). Annular dimensions were derived from preoperative and postoperative echocardiography or computed tomographic scans. If the annulus was oblong, the minor and major axes were averaged for analysis.

Kaplan-Meier actuarial estimates (expressed as \pm 1 standard error of the mean) and log-rank tests were calculated for comparative survival analysis with respect to primary end points and echocardiographic valve function Student $t$ tests and Wilcoxon tests were used for comparison of pretreatment and posttreatment variables. Normality tests were performed for identification of data distribution. Continuous data are reported as mean \pm 1 standard deviation or $95 \%$ confidence limits or as median plus IQRs (25th and 75th percentiles). SigmaPlot and SigmaStat 11.0 (Systat Software, San Jose, Calif), as well as SPSS 19 (IBM North America, New York, NY), were used for analysis. Cox univariable and multivariable proportional hazard analysis was attempted focusing on a composite end point $(>2+\mathrm{AR}$, reoperation, or death), but the model was unstable owing to too few events.

\section{Results-Three Cases of Reoperation}

One 46-year-old patient had fulminant prosthetic endocarditis, 4+ AR, dehiscence of the left ventricular outflow tract between the right and noncoronary sinuses, and destruction of the valve cusps 1 year postoperatively. The infected valve and graft were replaced with a homograft root, supplemented by Kay-Zubiate procedures (short interposition saphenous vein grafts to reconstruct the left and right main coronary ostia). Another patient underwent mechanical valve replacement inside the Dacron graft 3 years after the initial procedure owing to sudden recurrence of $4+$ AR and left ventricular dilatation. The original valve repair for severe AR had included PTFE suture neochord reconstruction of ruptured commissural suspensory chords, similar to those seen in truncal semilunar valves; the PTFE sutures had dehisced, allowing the fused left and right cusps to become flail. The third patient was a 48-year-old man who required a pericardectomy for symptoms of pericardial constriction 2 years after TD- $\mathrm{V}_{\mathrm{S}-\mathrm{MOD}}$, total arch replacement, and atrial septal defect repair. 

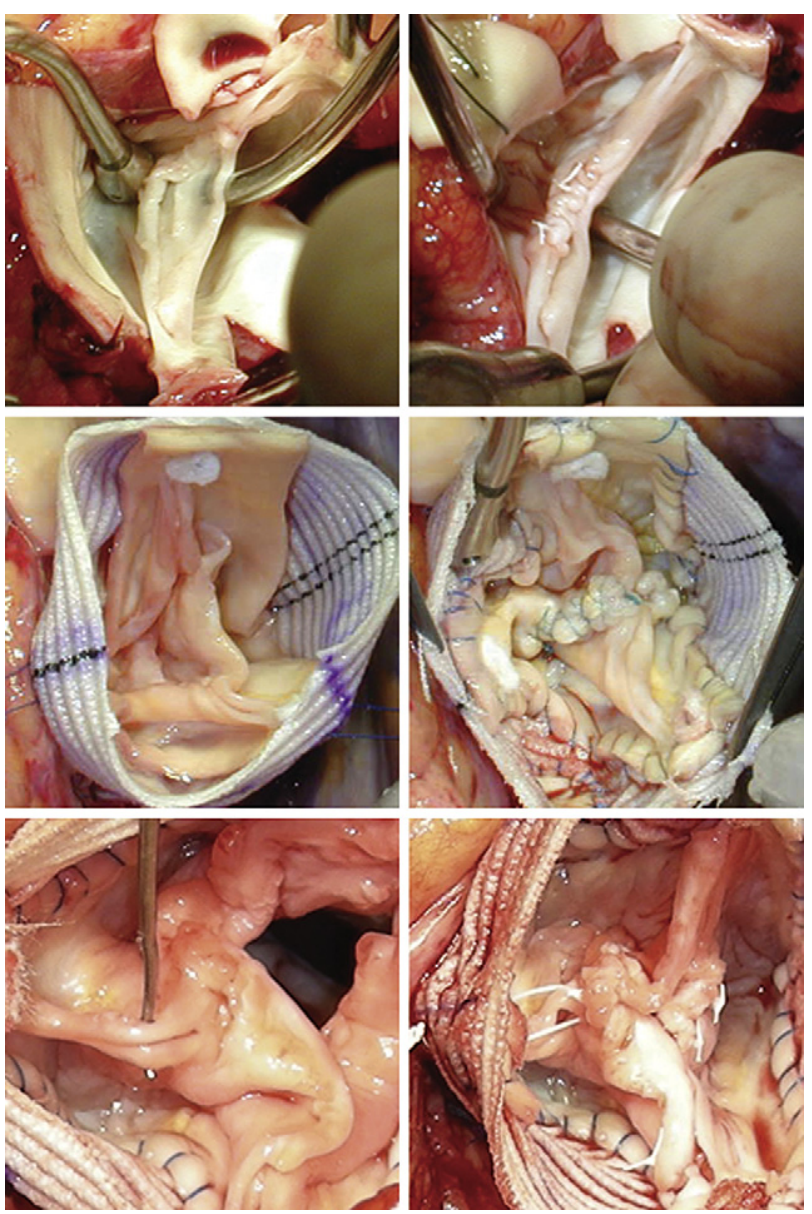

FIGURE E1. Upper images: Central free margin shortening on the fused right and left coronary cusps (Sievers' type S1/L-R configuration bicuspid aortic valve $[B A V])$. Left, There is minimal cusp fibrosis or calcification and aortic regurgitation $(A R)$ is mainly caused by cusp redundancy and prolapse (El Khoury type Ib AR). Right, Correction for prolapse to optimize coaptation level and height after placement of 2 central free margin shortening sutures. Middle images, Sievers' type S1/L-R BAV before (left) and after (right) triangular resection of the raphé between the fused left and right coronary cusps. Lower images: Left, Native suspensory cord to raphé free margin between the fused right and left coronary cusps in a Sievers' type S1/L-R BAV with considerable thickening and fibrosis of raphé. Right, Valve after neosuspensory-cord-creation using polytetrafluoroethylene (PTFE) sutures to the prolapsing left-right fused cusp free margin at the raphé and central free margin shortening of the noncoronary cusp.

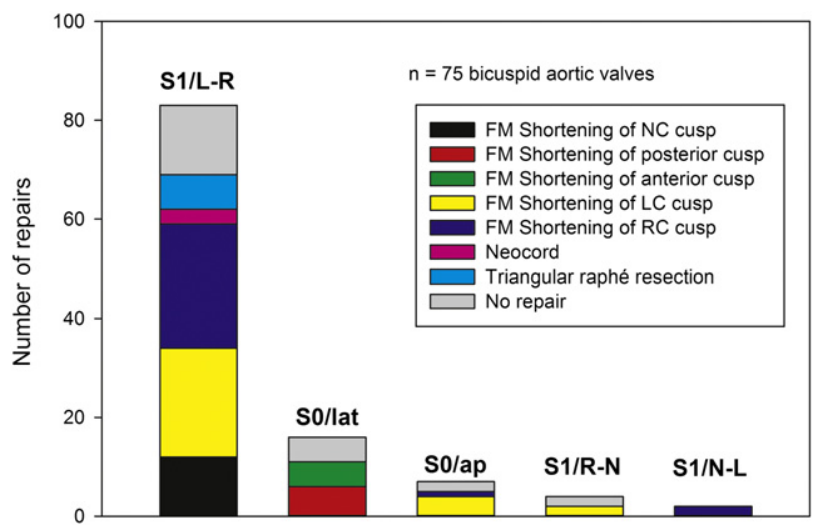

FIGURE E2. Types of cusp repair strategies performed at the time of reimplantation of the valve-sparing aortic root replacement stratified according to Sievers' types of bicuspid aortic valve configuration. FM, Cusp free margin; $N C$, noncoronary cusp; $L C$, left coronary cusp; $R C$, right coronary cusp. 